\title{
Infection Prevention and Control Risk Assessment: Approach for Early Identification of Harmful Practices and Improving Quality and Safety of Healthcare Service Delivery in Acute Healthcare Settings
}

\section{Hakizimana $B^{*}$}

Academic Unit for Infection Prevention and Control, Stellenbosch University, Stellenbosch, South Africa

\begin{abstract}
Background: Risk management is a process consisting of well-defined steps which, when taken in sequence, support better decision making by contributing to a greater insight into risks and their impacts. It is as much about identifying opportunity as is about avoiding losses. Effective prevention and control of infection must be part of everyday practice and be applied consistently by everyone.

Methods: The study was conducted at Tygerberg Hospital in 8 clinical areas/wards during a period of 3 weeks from 23 November 2013 to 9 October 2013. Risk Assessment IPC Inspection Checklist for healthcare institutions provided by the Unit for Infection Prevention and Control (UIPC) at Stellenbosch University was used for data collection. A feedback report was shared with the unit managers and ward in-charges, and the improvement plan was developed in collaboration with them. The follow-up was done to evaluate the implementation of the improvement plan. Data was analysed using Ms Excel.

Results: 6 out of $8(75 \%)$ wards complied with ward design, hand hygiene facilities available in all wards, 5 out of 8 wards $(62.5 \%)$ had inadequate and insufficient protective clothing, 7 out of $8(87.5 \%)$ wards did not have suitable patient toilet facilities. 7 out of 8 wards $(87.5 \%)$ had suitable sluice area, while 7 out of 8 wards $(87.5 \%)$ had appropriate treatment area. Quality of maintenance of aseptic procedures improved from $64 \%(18 / 28)$ to $85 \%(22 / 26)$ in patients with indwelling urinary catheter. The similar improvement was noted in patients with peripheral IV lines, from $81 \%(57 / 70)$ to $86 \%(48 / 56)$ as well as in the patients with wound, from $92 \%(22 / 24)$ to $100 \%(21 / 21)$.

Conclusion: 6 out of $8(75 \%)$ assessed wards complied against IPC standards. Conducting regular IPC assessment in clinical areas in collaboration with clinical staff (unit managers and in-charges) is essential to improve the quality and safety of healthcare service delivery. Significant improvement was noted in 7 wards during follow up assessment conducted one week after the initial risk assessment, whereby urinary catheter care improved from $64 \%$ to $85 \%$ (a $21 \%$ improvement) and peripheral IV line care improved from $81 \%$ to $86 \%$ (a $5 \%$ improvement). IPC and clinical teams (nurses, doctors, etc) should work hand in hand to improve the quality and safety of healthcare service delivery.
\end{abstract}

Keywords: HIPC risk assessment; Aseptic procedures; Infection prevention and control; Healthcare-associated infections; Clinical area/ ward; IPC precautions; Bundles of care; Hand hygiene facilities

\section{Introduction}

Good infection prevention and control is essential to ensure that people who use healthcare facilities receive safe and effective care [1-7]. Effective prevention and control of infection must be part of everyday practice and be applied consistently by everyone [1-10]. Good management and organizational processes are crucial to make sure that high standards of infection prevention and control are set up and maintained [1].

\section{Background}

Risk management is a process consisting of well-defined steps which, when taken in sequence, support better decision making by contributing to a greater insight into risks and their impacts. Risk Management is about identifying opportunity and avoiding losses [2,39]. The health care facility should provide appropriate care in suitable facilities consistent with good practice to protect patients, staff and others from the risks of acquiring healthcare associated infection (HAI) $[3,5-8]$.

\section{Methods}

The observational study was conducted at Tygerberg Hospital and it was part of the Risk Management module for Postgraduate Diploma in Infection Prevention and Control. Tygerberg Hospital is a 1310 beds academic tertiary referral hospital, located in Parow, Cape Town. The hospital was officially opened in 1976 and is the largest hospital in the Western Cape and the second largest hospital in South Africa. This The IPC risk assessment was conducted in 8 clinical areas/wards during a period of 3 weeks from 23 November 2013 to 9 October 2013. Six wards were visited in the first week, one ward in the second week, and the last ward in the third week. Risk Assessment IPC Inspection Checklist for healthcare institutions provided by Unit for Infection Prevention and Control (UIPC) was used for data collection. Clinical units/wards such as A4 East, A5 East, A5 West Medical High care, C1A Emergency Trauma, C2A Gynaeco-obstetrics High care, G6 (Ortho-pediatrics), G5 ENT (Ear-Nose-Throat) and F1 Medical Emergency were assessed

*Corresponding author: Hakizimana B, Academic Unit for Infection Prevention and Control, Faculty of Medicine and Health sciences, Stellenbosch University, Stellenbosch 7599, South Africa, Tel: +250788594903; E-mail: bonihak@yahoo.fr

Received: August 21, 2017; Accepted: September 07, 2017; Published: September 14, 2017

Citation: Hakizimana B (2017) Infection Prevention and Control Risk Assessment: Approach for Early Identification of Harmful Practices and Improving Quality and Safety of Healthcare Service Delivery in Acute Healthcare Settings. J Infect Dis Med 2: 114

Copyright: ( 2017 Hakizimana B. This is an open-access article distributed under the terms of the Creative Commons Attribution License, which permits unrestricted use, distribution, and reproduction in any medium, provided the original author and source are credited. 
Citation: Hakizimana B (2017) Infection Prevention and Control Risk Assessment: Approach for Early Identification of Harmful Practices and Improving Quality and Safety of Healthcare Service Delivery in Acute Healthcare Settings. J Infect Dis Med 2: 114.

and followed-up one week later. After carrying out Risk assessment for the Ward, a feedback report was provided to Unit manager and/or Shift leader and it contained the strengths and the weaknesses found during inspection. The feedback report was then discussed by both investigator and ward managers and the improvement action plan short and long term established. The re-evaluation appointment for short term action plan was fixed one week later. The purpose of revisiting the units/wards was to evaluate how recommendations given earlier were being implemented. Before starting risk assessment activity, the criteria for critical risk prone procedures were established and were used to decide whether the procedure found during Ward visit was safe or not. All urinary catheters, peripheral IV lines, CVP, endotracheal tube, nasogastric tube and wounds that were present during Ward visit were evaluated based on the criteria listed below. The photographs for critical malpractices were captured and shared with ward staff during the feedback session. Risk-prone procedures were evaluated according to the pre-determined criteria. Data was analysed using Ms Excel. The scoring was dichotomous; answers were "yes" or "no". The final score was obtained by adding the total number of "Yes" answers and divide by the total number of questions answered (including all "Yes" and "No" answers) excluding the "N/A" and then multiply by 100 to get the percentage. The compliance levels were calculated by using the compliance categories (compliant $85 \%$ or above, partial compliance 75 to $84 \%$, minimal compliance $74 \%$ or below). 4 Any procedure which has complied with criteria listed below, was classified as safe=low risk to acquiring Healthcare-associated infection (HAI), the ones which did not comply with any of the listed criteria, was classified as not safe or harmful (High risk to acquiring HAI) [4].

\section{Peripheral intravenous cannulation}

1. Intact fluid bag.

2. Connection with administration set.

3. Closed system is maintained.

4. Insertion site clean and dry and there is no sign of inflammation.

5. Injection ports remain clean and dry.

6. Point of administration set connection with intravascular catheter remains clean and dry.

7. There is free flowing of fluid (vein not obstructed).

8. The infusion is hanged onto drip stand properly.

\section{Central venous pressure catheters (CVP)}

1. Site clean and dry and there is no sign of inflammation.

2. Closed system is maintained.

3. The line is anchored (not suturing=stretches).

4. There is no three way tap in use.

5. There are no many infusion lines in the same CVP.

6. Injection ports remain clean and dry.

7. Point of administration set connection with intravascular catheter remains clean and dry.

8. There is free flowing of fluid (vein not obstructed).

9. The infusion is hanged onto drip stand properly.

\section{Urinary catheter (Indwelling urinary catheter)}

1. Catheter is secured on the patient thigh or lower abdomen.

2. Closed urinary drainage system is maintained.

3. The urinary drainage bag is off the floor.

4. The urinary drainage bag is below the level of the pelvis.

5. The tap of urinary drainage bag is clean and dry.

6. There is no solution instilled into the urinary drainage bag

\section{Wound}

1. The wound drain is clean and dry.

2. The wound dressing is clean and dry.

3. There is no visible leakage of blood on the dressing.

\section{Results and Discussion}

75\% (6 out of 8) assessed wards complied against IPC standards, one ward was partial compliant and the last one scored minimal compliance (Figure 1). Looking at the components of IPC assessment checklist: $75 \%$ (6 out of 8 ) wards were compliant against the ward design; hand hygiene facilities were present in all eight wards (Figure 2). Inadequate and insufficient protective clothing were observed in $62.5 \%$ of the wards ( 5 out of 8 wards) whilst $87.5 \%$ of the wards ( 7 out of 8 ) had not suitable patient toilet facilities. The suitable sluice area was present in $87.5 \%$ ( 7 out of 8 ) of the wards. Most of the wards, $87.5 \%$ (7 out of 8) had an appropriated treatment area. Aseptic procedures were not adequately managed at the time the initial assessment conducted (Table 1). Remarkable improvement was noted during the follow-up time (Table 2). Tables 2 and 3 summarize the improvement gained after the implementation of the short-term action plan. The quality of maintenance of aseptic procedures improved from $64 \%$ $(18 / 28)$ to $85 \%(22 / 26)$ in patients with indwelling urinary catheter. The similar improvement was noted in patients with peripheral IV lines, from $81 \%(57 / 70)$ to $86 \%(48 / 56)$ as well as in the patients with wound, from $92 \%(22 / 24)$ to $100 \%(21 / 21)$. Aseptic procedures were adequately maintained during both initial assessment and follow-up time for the patients with central venous pressure (CVP) commonly known as Central Line, endotracheal tube as well as the patients with nasogastric tube. Some malpractices have been observed, some of them were highlighted by some photographs captured during ward IPC assessment, such as inadequacy of some clinical care, like urinary catheter care (S Figure 1 and 2), peripheral IV line care (S Figure 3) and

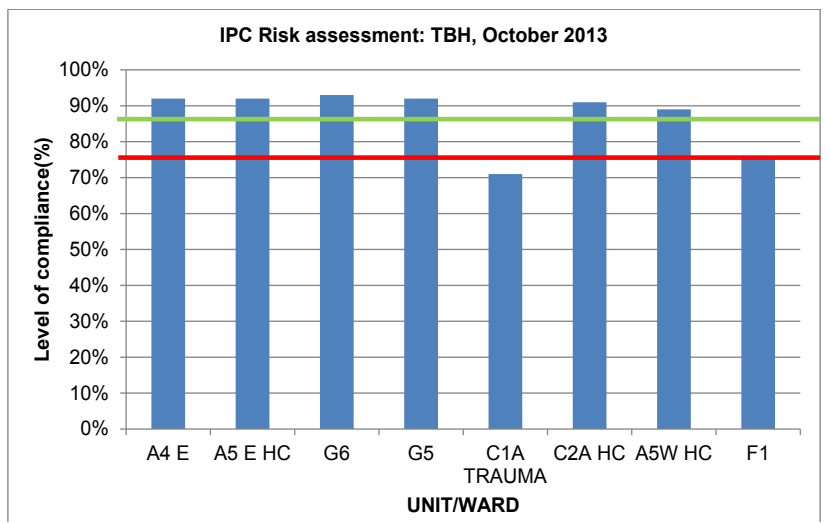

Figure 1: Overall score and level of compliance for the risk assessment carried out. 
Citation: Hakizimana B (2017) Infection Prevention and Control Risk Assessment: Approach for Early Identification of Harmful Practices and Improving Quality and Safety of Healthcare Service Delivery in Acute Healthcare Settings. J Infect Dis Med 2: 114.

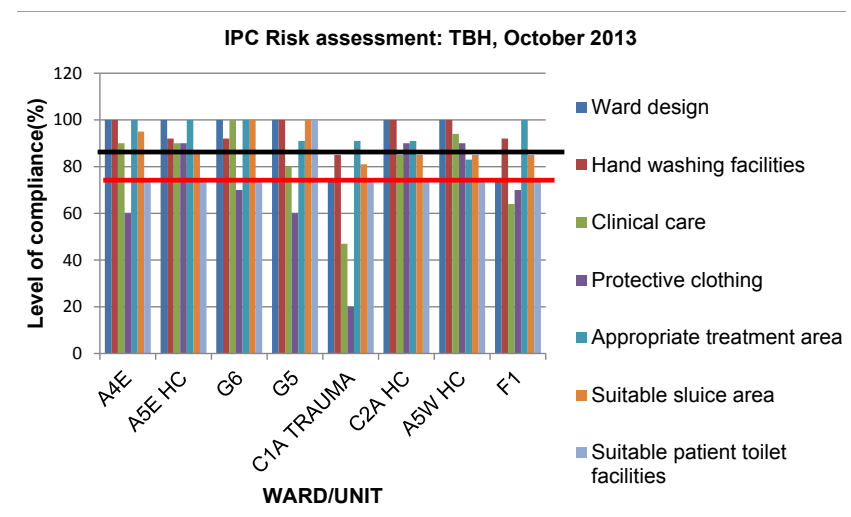

Figure 2: Overall compliance to the standard per ward/clinical area.

\begin{tabular}{|c|c|c|c|c|c|}
\hline Clinical care & $\begin{array}{c}\text { Total } \\
\text { cases }\end{array}$ & Safe & $\begin{array}{c}\text { Not } \\
\text { safe }\end{array}$ & $\begin{array}{c}\text { Compliance } \\
\text { (\%) }\end{array}$ & $\begin{array}{c}\text { Risk } \\
\text { stratification }\end{array}$ \\
\hline $\begin{array}{c}\text { Patients with urinary } \\
\text { catheter }\end{array}$ & 28 & 18 & 10 & $64 \%$ & High \\
\hline $\begin{array}{c}\text { Patients with peripheral } \\
\text { IV lines }\end{array}$ & 70 & 57 & 13 & $81 \%$ & High \\
\hline $\begin{array}{c}\text { Patients with CVP } \\
\text { patients with endotracheal } \\
\text { tube }\end{array}$ & 2 & 2 & 0 & $100 \%$ & Low \\
\hline $\begin{array}{c}\text { Patients with nasogastric } \\
\text { tube }\end{array}$ & 2 & 2 & 0 & 100 & Low \\
\hline Patients with wound & 24 & 22 & 2 & $92 \%$ & High \\
\hline Total of patients = 167 & & & & \\
\hline
\end{tabular}

Table 1: The situational risk prone procedures at the time of the initial assessment.

\begin{tabular}{|c|c|c|c|c|c|}
\hline Clinical care & $\begin{array}{c}\text { Total } \\
\text { cases }\end{array}$ & Safe & $\begin{array}{c}\text { Not } \\
\text { safe }\end{array}$ & $\begin{array}{c}\text { Compliance } \\
\text { (\%) }\end{array}$ & $\begin{array}{c}\text { Risk } \\
\text { stratification }\end{array}$ \\
\hline $\begin{array}{c}\text { Patients with urinary } \\
\text { catheter }\end{array}$ & 26 & 22 & 4 & $85 \%$ & High \\
\hline $\begin{array}{c}\text { Patients with peripheral } \\
\text { IV lines }\end{array}$ & 56 & 48 & 8 & $86 \%$ & High \\
\hline $\begin{array}{c}\text { Patients with CVP } \\
\text { patients with } \\
\text { endotracheal tube }\end{array}$ & 3 & 3 & 0 & $100 \%$ & Low \\
\hline $\begin{array}{c}\text { Patients with nasogastric } \\
\text { tube }\end{array}$ & 1 & 1 & 0 & 100 & Low \\
\hline Patients with wound & 21 & 21 & 0 & $100 \%$ & High \\
\hline Total of patients =148 & & & & \\
\hline
\end{tabular}

Table 2: The situational risk prone procedures at the follow up time.

\begin{tabular}{|c|c|c|c|}
\hline Clinical care & $\begin{array}{c}\text { Compliance } \\
\text { during risk } \\
\text { assessment } \\
\text { time }\end{array}$ & $\begin{array}{c}\text { Compliance post } \\
\text { assessment/ } \\
\text { Follow-up time }\end{array}$ & $\begin{array}{c}\text { Improvement } \\
\text { done }\end{array}$ \\
\hline $\begin{array}{c}\text { Patients with urinary } \\
\text { catheter }\end{array}$ & $64 \%$ & $85 \%$ & $21 \%$ \\
\hline $\begin{array}{c}\text { Patients with peripheral } \\
\text { IV lines }\end{array}$ & $81 \%$ & $86 \%$ & $5 \%$ \\
\hline Patients with CVP & $100 \%$ & $100 \%$ & Safe \\
\hline patients with endotracheal & $100 \%$ & $100 \%$ & Safe \\
\hline $\begin{array}{c}\text { tube } \\
\text { Patients with nasogastric } \\
\text { tube }\end{array}$ & 100 & 100 & Safe \\
\hline Patients with wound & $91 \%$ & $100 \%$ & $9 \%$ \\
\hline
\end{tabular}

Table 3: Findings from the implementation of the short-term improvement plan. wound care (S Figure 4). Loaded syringes were found in the wards for continuous bolus infusion. Some open ampoules were also observed in the medication area (S Figure 5). The multi-dose vials of lidocaine plunged with needles was also found in C1A Emergency Trauma (S Figure 6). Overfilled sharps containers were found in A5W H/C. Hand washing basins (HWB) were found dirty and drainage blocked, full of wastewater in some wards (S Figures 7 and 8). The open D-Germ bottles and the open liquid soap bottles were found in some wards (S Figure 9). Environmental cleaning had been also a challenge in some wards. Mops and buckets cleaning did not adhere to the environmental cleaning policy, whereby manual cleaning is applied by using cold water and normal liquid soap, which is different from the recommended hot water. In most of the wards, mops were found wet, dumped into bucket in the sluice or bed pan wash areas. Some mops were found hanged onto the sluice window. There was a colour coding policy for environmental cleaning whereby mops were identified, but in most of the wards, mops were hanged close together, therefore the risk of cross-contamination between mops was high (S Figures 10 and 11).

\section{Conclusion}

The findings from the IPC assessment conducted in the eight clinical wards showed that $75 \%$ (6 out of 8 ) the wards complied against IPC standards. Some malpractices which might expose patients to the risk of acquiring healthcare-associated infections were observed in most of all wards. Conducting regular IPC assessment in clinical areas in collaboration with clinical staff (unit managers and in-charges) is essential to improve the quality and safety of healthcare service delivery. Remarkable improvement was observed in 7 wards during follow-up done one week after the initial risk assessment visit, whereby urinary catheter care improved from $64 \%$ to $85 \%$ ( $21 \%$ improvement) and peripheral IV line care improved from $81 \%$ to $86 \%$ (5\% improvement). Only one C1A Emergency Trauma did not improve. Working together IPC team and Unit/Ward managers might be very fruitful to improve infection prevention and control and healthcare service delivery. All patients with peripheral IV lines and or urinary catheter should be monitored closely IPC in-service training should be encouraged in all clinical wards. Implementation of bundles for peripheral IV line, urinary catheter care and TB containment should be the best way for improvement: as observed, central line catheters and endotracheal tubes were well managed, that was the result of CLABSI and VAP bundles implemented already. IPC Link nurse or ward manager should always supervise and evaluate how clinical care is delivered. Mops, buckets cleaning and drying methods in place should be re-evaluated by UIPC. Clinical staff (doctors and nurses) should be encouraged to consult available IPC documents (manual, SOPs, policies, etc.) and cross-check with IPC team to improve patient care.

\section{Acknowledgements}

The authors are grateful for the support from the Unit managers, In-charges medical doctors and nurses of the visited wards at Tygerberg Hospital.

I would also like to convey my special gratitude to Mrs Magda Maureen Mocke for the supervision and guidance during this project.

My acknowledgement also goes to Prof. Shaheen Mehtar for encouraging and academic support during this project.

\section{References}

1. www.legislation.gov.uk

2. The Health Act (2006) Code of practice for the prevention and control of health care associated infections, $\mathrm{pp}:$ 1-37.

3. NHMRC (2010) Clinical Educators Guide for the prevention and control of infection in healthcare, pp: 1-16. 
Citation: Hakizimana B (2017) Infection Prevention and Control Risk Assessment: Approach for Early Identification of Harmful Practices and Improving Quality and Safety of Healthcare Service Delivery in Acute Healthcare Settings. J Infect Dis Med 2: 114.

4. S Mehtar (2010) Understanding infection prevention and control. JUTA.

5. WHO (2004) Practical guidelines for infection control in health care facilities.

6. Pittet D (2001) Compliance with hand disinfection and its impact on hospitalacquired infections. J Hosp Infect 48: S40-S46.

7. Pittet D (2000) Improving compliance with hand hygiene in hospitals. Infect Control Hosp Epidemiol 21: 381-386.
8. Pittet D, Allegranzi B, Sax H, Dharan S, Pessoa-Silva CL, et al. (2006) Evidence-based model or hand transmission during patient care and the role of improved practices. Lancet Infect Dis 6: 641-652.

9. Sax H, Allegranzi B, Uçkay I, Larson E, Boyce J, et al. (2007) My five moments for hand hygiene: A user-centred design approach to understand, train, monitor and report hand hygiene. J Hosp Infect 67: 9-21.

10. WHO (2017) Save lives: Clean your hands - WHO's global annual campaign. 